\title{
Assessment of proliferating cell nuclear antigen (PCNA) expression at the invading front of oral squamous cell carcinoma
}

\author{
Emily Ming-Chieh Lu, Jithendra Ratnayake * ${ }^{*}$ and Alison Mary Rich
}

\begin{abstract}
Background: Accurate prediction of the behaviour of oral squamous cell carcinoma (OSCC) is necessary to determine prognosis and provide appropriate treatment. Therefore, it is important to investigate potential prognostic markers to determine their predictive ability. Histological assessment of specific features at the invading front of oral squamous cell carcinomas has shown to provide accurate and reproducible prognostic information. Proliferating cell nuclear antigen (PCNA) is a nuclear marker known to reflect cell turnover and may be used as a marker for tumour aggressiveness.

Methods: Twenty cases of OSCC were histologically assessed to evaluate the correlation between proliferating cell nuclear antigen expression and invasive front grading. Each case was first assessed on a haematoxylin and eosin stained slide and an invading front grading (IFG) score was determined. In order to obtain a PCNA score, immunohistological staining was carried out using the peroxidase-labelled streptavidin-biotin technique with the monoclonal antibody PC10.
\end{abstract}

Results: In all cases, tumour islands had a periphery of intensely stained proliferating cell nuclear antigen-positive epithelial cells. The average IFG score was $8 \pm 1.8$, and the average PCNA score was $75 \% \pm 11.2$. Regression analysis was done using data from the IFG score and PCNA score and taking the latter as the predictor variable. The Pearson correlation coefficient was 0.134 , with a $p$-value of 0.572 .

Conclusion: Since the correlation between PCNA score and IFG score was not significant $(p>0.05)$, we conclude that there is no association between cell proliferation at the invading tumour front and the histological grading of OSCC.

Keywords: Proliferating cell nuclear antigen, Oral squamous cell carcinoma, Invasive tumour front, Cell proliferation, Prognosis

\section{Background}

Oral cancer is a serious and growing problem in many parts of the globe. Oral and pharyngeal cancer, grouped, is the sixth most common cancer in the world [1]. According to the global cancer statistics (GLOBOCAN 2018), 177,384 deaths were reported due to cancers of the lip and oral cavity, and it is common in high-risk regions such as South Asia $[2,3]$. Despite advances in surgery and various adjunctive therapies, there is no evidence to suggest that the

\footnotetext{
* Correspondence: jithendra.ratnayake@otago.ac.nz

Faculty of Dentistry, The University of Otago, PO Box 647, 310 Great King Street, Dunedin 9016, New Zealand
}

mortality of OSCC is increasing, and those that survive have to cope with debilitating side effects of treatment $[4,5]$.

Accurate staging is essential to evaluate treatment protocols and provide prognostic information for patients with oral squamous cell carcinoma (OSCC). Conventionally, this is based on the clinical assessment of tumour size, lymph node involvement and presence of distant metastases, the TNM system. The three parameters are tallied to give an overall stage; the higher the stage the worse the prognosis. While widely used, the TNM system has been criticised for its inability to predict survival in OSCC [6]. Modifications including the addition of the site of the tumour and a histopathological assessment led to the development of the 
STNMP system with a weighted numerical score for all five components [7]. While receiving some support, Langdon et al. found that the STNMP system was no more accurate in predicting survival than the TNM system [8] and STNMP staging is not in common usage [9].

Altered rates of cell proliferation are one of the hallmarks of tumour progression, and therefore, assessment of this feature may be useful in predicting patient prognosis $[10,11]$. Proliferating Cell Nuclear Antigen (PCNA) is a nuclear protein and marker of cell proliferation. PCNA is strongly related to prognosis and survival in most types of solid malignancies, such as colorectal cancer and breast cancer [12-14]. It is known to accurately reflect rates of cellular proliferation and DNA synthesis since it accumulates in late $\mathrm{G} 1$ and early S phase $[15,16]$. A dysregulation in cell proliferation could be assessed using PCNA, with an increase in PCNA immunoreactivity associated with an increase in cell proliferation [17].

Previous studies have demonstrated a positive correlation between the expression of PCNA and histological grading of OSCC. A difference in the expression of PCNA was found between normal and dysplastic epithelium [18] and between normal and malignant lesions [19]. Furthermore, PCNA expression showed a positive correlation with histological grading [20], with an increase in PCNA expression being associated with a poorly differentiated tumour and a reduced expression of PCNA suggestive of well-differentiated OSCC [21].

All of the aforementioned studies have, however, used the conventional histological grading system, which assesses the differentiation of the tumour as a whole. An alternative histological assessment is the invasive front grading (IFG) system which assesses the histological grading of the tumour at the invasive front only. The invasive tumour front (ITF) is a region of the tumour which contains cells with higher proliferative activity and [22] and a lower degree of differentiation [23]. Therefore, the ITF is considered the most important region of the tumour in determining prognosis and hence it was proposed that the IFG system would allow more accurate diagnosis and staging of cancer compared to the conventional histological grading [10].

The IFG system comprises four morphologic features; degree of keratinisation, nuclear polymorphism, pattern of invasion and host response [10], with each feature assigned a numerical value, generating an overall IFG score. The minimum score of 4 is the lowest IFG score obtainable and suggests a tumour with the best prognosis. Conversely, a maximum score of 16 suggests a tumour with the worst possible prognosis. So far, no studies have investigated the correlation between the expression of PCNA and IFG score at the ITF of OSCCs. Therefore, the main aim of this study was to investigate the correlation between the expression of PCNA at the invasive tumour front and the IFG histological grading in OSCCs.

\section{Methods \\ Selection of study specimens}

Ethical approval was obtained from the Faculty of Dentistry, University of Otago Human Ethics committee. Specimens used for the study were all formalin-fixed, paraffin-embedded tissues that had been diagnosed with OSCC from the Oral Pathology Centre, Faculty of Dentistry, University of Otago. For this study, oral squamous cell carcinoma (OSCC) arising in the oral cavity and lip vermilion was used. Specimens from the skin of the lips and face were excluded. The most recent cases of OSCC were reviewed until 20 suitable cases had been collected for the study. Inclusion criteria were the presence of the ITF, intra-oral site, patient consent to the use of the biological material after diagnostic procedures were complete for teaching and/or research purposes and there being sufficient material in the block. For each chosen case, a haematoxylin and eosin (H\&E) slide was histologically assessed, and a PCNA score was obtained after immunohistological staining.

\section{Histological evaluation}

Each H\&E stained slide was assessed histologically according to the criteria outlined by Bryne [10] (Table 1). An IFG score was thus generated, where an increase in score is associated with a decrease in prognosis. Each $\mathrm{H}$ \&E slide was initially evaluated by the primary author (EL) and later confirmed by AR, a consultant oral pathologist; this was repeated 2 weeks later to check the correlation. Where there was a discrepancy between examiners, the score from the most experienced examiner (AR) was taken. Each histological sample was then assigned an IFG score, as well as a conventional histological WHO grading [24].

\section{Immunohistochemistry}

A peroxidase-labelled streptavidin-biotin technique was performed, similar to previously described [20, 25]. Briefly, $4 \mu \mathrm{m}$ thick tissue sections were deparaffinsed in xylene, rehydrated in graded absolute alcohols before washing in running water. The pre-treatment step involved treating the slides with proteinase K (DakoCytomation, Lot 00004344) for $10 \mathrm{~min}$, followed by immersion in citrate buffer and heating in a microwave at $90^{\circ} \mathrm{C}$ for $10 \mathrm{~min}$. The slides were then allowed to cool to room temperature before being washed under running water. All slides were then treated with $3 \% \mathrm{H}_{2} \mathrm{O}_{2}$ (BDH Laboratory Supplies Poole, England, Lot K32950980) in methanol for $15 \mathrm{~min}$ to block the endogenous peroxidase activity. To block nonspecific binding sites, $5 \%$ fetal calf serum (25ul frozen aliquot FCS: $5 \mathrm{ml} \mathrm{PBS)}$ was added. This was followed by 
Table 1 The Invading tumour front grading system used to generate total IFG score, as developed by Bryne et al. [10]

\begin{tabular}{|c|c|c|c|c|}
\hline \multirow[t]{2}{*}{ Morphological feature } & \multicolumn{4}{|l|}{ Score } \\
\hline & 1 & 2 & 3 & 4 \\
\hline Degree of keratinisation & $\begin{array}{l}\text { Highly keratinised } \\
\text { (>50\% of the cells) }\end{array}$ & $\begin{array}{l}\text { Moderately keratinised } \\
\text { (20-50\% of the cells) }\end{array}$ & $\begin{array}{l}\text { Minimal keratinisation } \\
(5-20 \% \text { of the cells) }\end{array}$ & $\begin{array}{l}\text { No keratinisation } \\
\text { (0-5\% of the cells) }\end{array}$ \\
\hline Nuclear polymorphism & $\begin{array}{l}\text { Little nuclear polymorphism } \\
\text { (>75\% mature cells) }\end{array}$ & $\begin{array}{l}\text { Moderately abundant nuclear } \\
\text { polymorphism } \\
\text { (50-75\% mature cells) }\end{array}$ & $\begin{array}{l}\text { Abundant nuclear } \\
\text { polymorphism } \\
\text { (25-50\% mature cells) }\end{array}$ & $\begin{array}{l}\text { Extreme nuclear polymorphism } \\
\text { (0-25\% mature cells) }\end{array}$ \\
\hline Pattern of invasion & $\begin{array}{l}\text { Pushing, well delineated } \\
\text { infiltrating borders }\end{array}$ & $\begin{array}{l}\text { Infiltrating, solid cords, bands } \\
\text { and /or strands }\end{array}$ & $\begin{array}{l}\text { Small groups of cords of } \\
\text { infiltrating cells }(n>15)\end{array}$ & $\begin{array}{l}\text { Marked and widespread cellular } \\
\text { dissociation in small groups and /o } \\
\text { in single cells }(n<15)\end{array}$ \\
\hline $\begin{array}{l}\text { Host response } \\
\text { (inflammatory cell } \\
\text { infiltration) }\end{array}$ & Marked & Moderate & Slight & None \\
\hline
\end{tabular}

application of the monoclonal anti-PCNA antibody PC10 (DakoCytomation, Lot 00005087). Sections were then treated with the biotinylated link and subsequently with the streptavidin horseradish peroxidase (LSAB kit, DakoCytomation, Lot 00003534). In order to visualise the peroxidase activity, slides were saturated with the chromogen, diaminobenzidine hydrochloride (DAB, DakoCytomation, Lot 016067) in a ratio of $1 \mathrm{ml}$ DAB buffer: 1 drop DAB substrate. All of the previous steps were followed by a wash in PBS, unless otherwise stated. Finally, all slides were counterstained with Gills haematoxylin, washed in Scotts tap water before coverslips were applied.

All slides contained a section of normal epithelium to serve as a both positive and an internal control. A negative control in which the primary antibody (PC10) was omitted was included in each batch of slides stained.

\section{Immunohistochemical evaluation: expression of PCNA}

Each specimen was orientated by firstly identifying the epithelium and then locating the tumour front in the deepest invading area of the tumour. Counting was done systematically, whereby malignant keratinocytes in alternating high power fields at the invading front were counted until a total of 200 cells was reached. A PCNA positive cell was defined as one with clear, distinct brown nuclear staining. The number of positive cells was expressed as a percentage of the total number counted to generate a PCNA score [25]. Intensity of PCNA expression was recorded with reference to a known positive control and was reviewed and verified by a specialist oral pathologist. Grade 1 denoted intense PCNA staining, grade 2 moderate PCNA staining and grade 3 indicated weak staining. The calibration process was carried out on a total of six slides where agreement was reached for each of the three grading intensities. Following calibration, each slide was assessed independently by two examiners. The final number of PCNA positive cells recorded for each slide was obtained from taking the average positive cell counts from the two examiners, EL and AR. An appropriate level of inter-examiner agreement was achieved across all slides (Cohen's Kappa coefficient $>0.6$ ). To aid in the comparison between slides, images of the cells in the invading front were captured digitally for later reference.

\section{Statistical analysis}

Regression analysis was performed using Statistical Package for Social Studies software (SPSS version 24; IBM Corporation, Armonk, NY, USA) to compare variables. The level of significance was set at $p<0.05$ ).

\section{Results}

\section{Invasive front grading}

At the invading front of each specimen, four morphological features were assessed on $H \& E$ slides as outlined in Table 1. Each H\&E section was assessed histologically for their IFG scores according to the criteria outlined by Bryne [10], and matched with their existing conventional histological WHO grading [24]. The total IFG score and the scores for each morphological feature for each specimen are shown in Table 2. The average IFG score was 8 with a standard deviation (SD) of 1.84 . The mode score was 7 , and the score range was between 5 and 13 inclusive. The mode score for each morphologic feature was also calculated (Table 3). A mode score of 1 for "host response" indicated a marked host response in most of the specimens. Both "Degree of keratinisation" and "pattern of response" had a mode score of 2 , indicating that in most cases $20-50 \%$ of cells were keratinised cells at the tumour front, and there were infiltrating, solid cords, bands or strands invading the connective tissue. Lastly, "nuclear polymorphism" had a mode score of 3 , indicating that $25-50 \%$ mature cells at the invading front showed this feature (Table 3 ). Figure 1 shows the $\mathrm{H} \& \mathrm{E}$ section of a specimen and its IFG score.

\section{PCNA quantification and expression}

Table 4 shows the PCNA score (\%), and the intensity of PCNA immunostaining expressed as a grade for 
Table 2 H\&E histological evaluation using the IFG grading system [10]

\begin{tabular}{|c|c|c|c|c|c|}
\hline OSCC cases & Degree of keratinization & Nuclear polymorphism & Pattern of invasion & Host response & Total score \\
\hline 1) & 1 & 3 & 2 & 1 & 7 \\
\hline 2) & 1 & 2 & 2 & 1 & 6 \\
\hline 3) & 2 & 1 & 1 & 1 & 5 \\
\hline 4) & 2 & 3 & 1 & 1 & 7 \\
\hline 5) & 2 & 4 & 1 & 2 & 9 \\
\hline 6) & 1 & 3 & 2 & 1 & 7 \\
\hline 7) & 2 & 3 & 2 & 2 & 9 \\
\hline 8) & 3 & 3 & 2 & 1 & 9 \\
\hline 9) & 2 & 3 & 3 & 1 & 9 \\
\hline 10) & 3 & 4 & 3 & 3 & 13 \\
\hline 11) & 2 & 3 & 2 & 3 & 10 \\
\hline 12) & 2 & 4 & 3 & 1 & 10 \\
\hline 13) & 2 & 3 & 2 & 1 & 8 \\
\hline 14) & 1 & 2 & 2 & 1 & 6 \\
\hline 15) & 1 & 2 & 3 & 1 & 7 \\
\hline 16) & 1 & 2 & 2 & 1 & 6 \\
\hline 17) & 1 & 4 & 2 & 2 & 9 \\
\hline 18) & 3 & 2 & 1 & 1 & 7 \\
\hline 19) & 2 & 2 & 2 & 2 & 8 \\
\hline 20) & 1 & 2 & 3 & 2 & 8 \\
\hline
\end{tabular}

each specimen. PCNA scores were computed by quantifying the number of cells with a distinct brown nuclear staining (PCNA positive cells) out of a total of 200 cells counted at the invading front. Intensity of staining was compared to a known control and defined as 1 =intense, $2=$ moderate or 3 =weak. The average PCNA score was $75.0 \%$, SD $11.2 \%$. PCNA expression was intense (grade 1) in $45 \%$ of the cases, moderate (grade 2) in $40 \%$ of the cases, and weak (grade 3) in $15 \%$ of the cases. The mode intensity score was 1.

In all cases, epithelial islands at the tumour front had a periphery of intensely stained PCNA positive epithelial cells, surrounding prickle cells (Fig. 2). The prickle cells were in most cases moderately or weakly stained. However, no staining was observed in some specimens. Many islands had an inner core of keratin, which was unstained.

Table 3 Invasive front grading (IFG). Mode scores for individual morphologic feature

\begin{tabular}{ll}
\hline Morphologic features & Mode score \\
\hline Degree of keratinisation & 2 \\
Nuclear polymorphism & 3 \\
Pattern of invasion & 2 \\
Host response & 1 \\
\hline
\end{tabular}

\section{Regression analyses}

To assess the relationship between PCNA expression and IFG and taking the intensity of staining as the predictor variable, the following model was generated: IFG $=9.333-7.84$ intensity. The $p$-value was 0.179 , and hence there was no association between intensity of PCNA staining and IFG score in this study (Table 4). Using PCNA score as the predictor variable, no significant relationship was found between PCNA score and

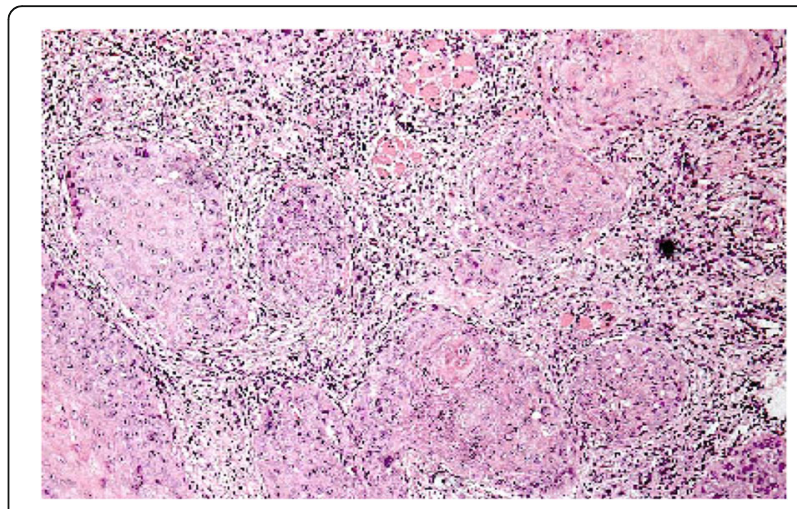

Fig. $1 \mathrm{H} \& \mathrm{E}$ section showing malignant epithelial islands at the ITF ( $\times 10$ objective lens). The total IFG score was 7 (degree of keratinisation $=1$; nuclear polymorphism $=3$; pattern of invasion $=2$; host response $=1$ ) 
Table 4 Summary of PCNA scores (\%), intensity of PCNA staining, IFG scores and conventional histological grading scores for OSCC cases

\begin{tabular}{|c|c|c|c|c|c|}
\hline OSCC cases & No. of PCNA +ve cells & PCNA score \% (out of 200) & Intensity of staining & IFG Score & Conventional histological grading \\
\hline 1) & 184 & 92 & 2 & 7 & 1 \\
\hline 2) & 103 & 51.5 & 3 & 6 & 1 \\
\hline 3) & 157 & 78.5 & 2 & 5 & 1 \\
\hline 4) & 169 & 84.5 & 2 & 7 & 1 \\
\hline 5) & 127 & 63.5 & 1 & 9 & 2 \\
\hline 6) & 137 & 68.5 & 3 & 7 & 1 \\
\hline 7) & 176 & 88 & 1 & 9 & 2 \\
\hline 8) & 163 & 81.5 & 1 & 9 & 2 \\
\hline 9) & 139 & 69.5 & 1 & 9 & 1 \\
\hline 10) & 148 & 74 & 2 & 13 & 2 \\
\hline 11) & 179 & 89.5 & 2 & 10 & 2 \\
\hline 12) & 149 & 74.5 & 1 & 10 & 1 \\
\hline 13) & 120 & 60 & 2 & 8 & 1 \\
\hline 14) & 165 & 82.5 & 1 & 6 & 1 \\
\hline 15) & 139 & 69.5 & 1 & 7 & 1 \\
\hline 16) & 147 & 73.5 & 2 & 6 & 1 \\
\hline 17) & 150 & 75 & 1 & 9 & 1 \\
\hline 18) & 116 & 58.2 & 3 & 7 & 2 \\
\hline 19) & 178 & 89 & 1 & 8 & 1 \\
\hline 20) & 154 & 77 & 2 & 8 & 1 \\
\hline
\end{tabular}

intensity of PCNA staining $(p=0.068)$ (Table 4$)$. A significant relationship $(p=0.012)$ between IFG score and the conventional histological grading system was found with regression analysis using IFG score as the predictor variable (Table 4). To determine whether there was any relationship between PCNA score and IFG score, PCNA score was taken as the predictor variable (Table 4) and the

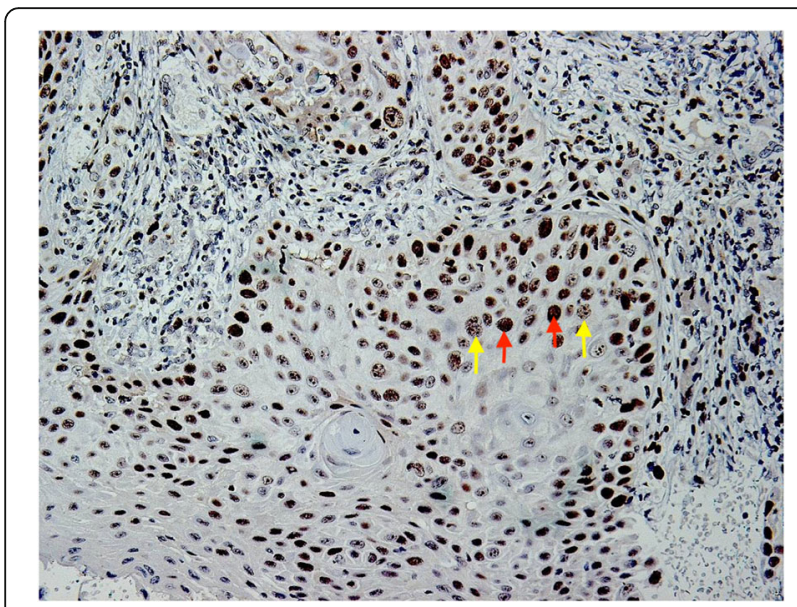

Fig. 2 PCNA expression at the ITF showing intensely stained nucleus (red arrow), surrounded by granular prickle cells (yellow arrows). ( $\times 20$ objective) regression line generated follows the model: $\mathrm{IFG}=6.343+$ 0.022 PCNA. This association was not significant $(p>$ $0.05)$. The Pearson correlation coefficient $(\mathrm{R})$ was 0.134 with a $p$-value of 0.572 . In addition, the Spearman correlation coefficient $(\rho)$ was found to be $0.143 ; p=0.547$.

\section{Discussion}

The present study sought to assess the correlation between the expression of PCNA at the ITF and the IFG score of OSCC cases from archival blocks. Our study showed that there was an average of $75 \%$ PCNA positive cells at the ITF. It is difficult to compare this finding with that in the literature as most studies investigating PCNA expression were exclusive to the ITF $[17,18,26]$ and the one study [27] which specifically examined the expression of PCNA at the ITF did not stipulate the WHO grading and the location of OSCC samples in the oral cavity.

The intensity of PCNA positivity were mostly either intense or moderate ( 45 and $40 \%$ of cases respectively). This intense positivity observed at the periphery of the malignant epithelial islands has been previously noted $[19,26,28]$ and suggests that this is the main site of cellular proliferation. The variation in PCNA expression, as observed in this study could be related to technical factors such as duration of fixation, size of tissue block and 
the type of fixative [29]. While the latter was consistent across all cases in this study, the first two factors could not be controlled. Furthermore, the variability in marker expression could be due to the fact that PCNA has a long half-life of $20 \mathrm{~h} \mathrm{[30].} \mathrm{Therefore,} \mathrm{it} \mathrm{is} \mathrm{possible} \mathrm{that}$ non-cycling cells may show residual PCNA expression and result in an overestimation of the proliferating population.

The histological assessment using the IFG generated scores suggested that most cases in this study had a reasonable prognosis (Table 3 ). There was also positive association between IFG scores and the conventional histological grade, suggesting a consistency between the two systems [10].

Overall, the study showed no association between the expression of PCNA (percentage score and intensity grading) and the IFG score at the ITF. While the data seems to contrast with earlier studies which showed a positive correlation between PCNA and histological grade [21, 26], it is consistent with the findings from Tsai and Jin which showed a lack of correlation between PCNA expression and histological grading [17]. All of the aforementioned studies have used the conventional histological grading in its assessment, rather than the ITF grading system employed in this study [10].

The lack of correlation between PCNA expression and histological grading should not be unexpected, however, given that there is evidence to suggest an absence of an association between PCNA expression and patient survival $[31,32]$. A more recent study also showed that the expression of proliferation markers Ki67 and AgNOR at the ITF were not associated with prognosis of OSCC [33]. However, overexpression of PCNA in conjunction with p53 was associated with OSCCs with a poor prognosis [27]. Similarly, overexpression of PCNA and EGFR was associated with poor survival [34]. This suggests that elevated levels of PCNA, in the presence of increased expression of a supplementary biomarker improves prognostic determination. Therefore, the long-term follow-up of our patient cases would determine whether the IFG grading system and/ or PCNA score has any relationship with patient survival.

\section{Conclusions}

The study showed no correlation between the expression of PCNA at the ITF and the IFG scores of OSCCs. Therefore, there was no association between cell proliferation activity and histological grading at the invading tumour front.

\section{Abbreviations}

IFG: Invading front grading; ITF: Invasive tumour front; OSCC: Oral squamous cell carcinoma; PBS: Phosphate buffer saline; PCNA: Proliferating cell nuclear antigen

Acknowledgements

Not applicable.
Authors' contributions

EM-CL and AMR conceptualised the study, completed data analysis, and drafted the manuscript. JR was a major contributor in writing the manuscript. All authors read and approved the final manuscript.

\section{Funding}

None.

Availability of data and materials

The datasets used and/or analysed during the current study are available from the corresponding author on reasonable request.

\section{Ethics approval and consent to participate}

This study was approved by the Faculty of Dentistry, University of Otago Human Ethics committee. All procedures performed in studies involving human participants were in accordance with the ethical standards of the institutional and/or national research committee and with the 1964 Helsinki Declaration and its later amendments or comparable ethical standards. Informed written consent was obtained from all individual participants included in the study.

\section{Consent for publication}

Not applicable.

\section{Competing interests}

Alison Mary Rich is an associate editor of the BMC Oral Health Journal. The authors declare that they have no competing interests with respect to the authorship and/or publication of this article.

\section{Received: 6 June 2019 Accepted: 15 October 2019}

\section{-}

\section{References}

1. Warnakulasuriya S. Global epidemiology of oral and oropharyngeal cancer. Oral Oncol. 2009;45(4-5):309-16.

2. Bray F, Ferlay J, Soerjomataram I, Siegel RL, Torre LA, Jemal A. Global cancer statistics 2018: GLOBOCAN estimates of incidence and mortality worldwide for 36 cancers in 185 countries. CA Cancer J Clin. 2018;68(6):394-424.

3. Warnakulasuriya S. Living with oral cancer: epidemiology with particular reference to prevalence and life-style changes that influence survival. Oral Oncol. 2010;46(6):407-10.

4. Rivera C. Essentials of oral cancer. Int J Clin Exp Pathol. 2015;8(9):11884.

5. Boyle P, Macfarlane GJ, Maisonneuve P, Zheng T, Scully C, Tedesco B. Epidemiology of mouth cancer in 1989: a review. J R Soc Med. 1990;83(11):724-30.

6. Massano J, Regateiro FS, Januario G, Ferreira A. Oral squamous cell carcinoma: review of prognostic and predictive factors. Oral Surg Oral Med Oral Pathol Oral Radiol Endod. 2006;102(1):67-76.

7. Rapidis AD, Langdon JD, Patel MF, Harvey PW. STNMP: a new system for the clinico-pathological classification and identification of intra-oral carcinomata. Cancer. 1977;39(1):204-9.

8. Langdon JD, Rapidis AD, Harvey PW, Patel MF. STNMP-a new classification for oral cancer. Br J Oral Surg. 1977;15(1):49-54.

9. Rich AM, Radden BG. Squamous cell carcinoma of the oral mucosa: a review of 244 cases in Australia. J Oral Pathol. 1984;13(5):459-71.

10. Bryne M. Is the invasive front of an oral carcinoma the most important area for prognostication? Oral Dis. 1998;4(2):70-7.

11. Hall PA, Levison DA. Review: assessment of cell proliferation in histological material. J Clin Pathol. 1990:43(3):184-92.

12. al-Sheneber IF, Shibata HR, Sampalis J, Jothy S. Prognostic significance of proliferating cell nuclear antigen expression in colorectal cancer. Cancer. 1993;71(6):1954-9

13. Shrestha P, Yamada K, Wada T, Maeda S, Watatani M, Yasutomi M, et al. Proliferating cell nuclear antigen in breast lesions: correlation of c-erbB-2 oncoprotein and EGF receptor and its clinicopathological significance in breast cancer. Virchows Arch A Pathol Anat Histopathol. 1992;421(3):193-202.

14. Tubiana M, Courdi A. Cell proliferation kinetics in human solid tumors: relation to probability of metastatic dissemination and long-term survival. Radiother Oncol. 1989;15(1):1-18.

15. Kurki P, Ogata K, Tan EM. Monoclonal-antibodies to proliferating cell nuclear antigen (Pcna) Cyclin as probes for proliferating cells by 
immunofluorescence microscopy and flow-cytometry. J Immunol Methods. 1988:109(1):49-59.

16. Yonemura Y, Kimura H, Fushida S, Tugawa K, Nakai Y, Kaji M, et al. Analysis of proliferative activity using anti-proliferating cell nuclear antigen antibody in gastric cancer tissue specimens obtained by endoscopic biopsy. Cancer. 1993;71(8):2448-53.

17. Tsai ST, Jin YT. Proliferating cell nuclear antigen (PCNA) expression in oral squamous cell carcinomas. J Oral Pathol Med. 1995;24(7):313-5.

18. Girod SC, Pape HD, Krueger GR. p53 and PCNA expression in carcinogenesis of the oropharyngeal mucosa. Eur J Cancer B Oral Oncol. 1994;30B(6):419-23.

19. Tsuji T, Sasaki K, Kimura Y, Yamada K, Mori M, Shinozaki F. Measurement of proliferating cell nuclear antigen (PCNA) and its clinical application in oral cancers. Int J Oral Maxillofac Surg. 1992;21(6):369-72.

20. Shin DM, Voravud N, Ro JY, Lee JS, Hong WK, Hittelman WN. Sequential increases in proliferating cell nuclear antigen expression in head and neck tumorigenesis: a potential biomarker. J Natl Cancer Inst. 1993;85(12):971-8.

21. Poosarla C, Ramesh M, Ramesh K, Gudiseva S, Bala S, Sundar M. Proliferating cell nuclear antigen in premalignancy and oral squamous cell carcinoma. J Clin Diagn Res. 2015;9(6):ZC39-41.

22. Piffko J, Bankfalvi A, Ofner D, Kusch F, Bocker W, Joos U, et al. In situ assessment of cell proliferation at the invasive front of oral squamous cell carcinomas. Virchows Arch. 1996:429(4-5):229-34.

23. Piffko J, Bankfalvi A, Ofner D, Bryne M, Rasch D, Joos U, et al. Prognostic value of histobiological factors (malignancy grading and AgNOR content) assessed at the invasive tumour front of oral squamous cell carcinomas. $\mathrm{Br} J$ Cancer. 1997;75(10):1543-6.

24. Barnes LEJ, Reichart P, Sidransky D. World Health Organization classification of tumours: pathology and genetics of head and neck tumours; 2005.

25. Chiang CP, Lang MJ, Liu BY, Wang JT, Leu JS, Hahn L, et al. Expression of proliferating cell nuclear antigen (PCNA) in oral submucous fibrosis, oral epithelial hyperkeratosis and oral epithelial dysplasia in Taiwan. Oral Oncol. 2000;36(4):353-9.

26. Lan HA, Zain RB, Saitoh M, Muramatsu Y, Shrestha P, Mori M. Proliferating cell nuclear antigen (PCNA) and p53 in epithelial dysplasia and squamous cell carcinoma of oral mucosa--a marker for poor tumor differentiation, increasing nuclear atypia and invasiveness? Anticancer Res. 1996;16(5B):3059-65.

27. Kato K, Kawashiri S, Yoshizawa K, Kitahara H, Okamune A, Sugiura S, et al. Expression form of p53 and PCNA at the invasive front in oral squamous cell carcinoma: correlation with clinicopathological features and prognosis. J Oral Pathol Med. 2011;40(9):693-8.

28. Tsuji T, Shrestha P, Yamada K, Takagi H, Shinozaki F, Sasaki K, et al. Proliferating cell nuclear antigen in malignant and pre-malignant lesions of epithelial origin in the oral cavity and the skin: an immunohistochemical study. Virchows Arch A Pathol Anat Histopathol. 1992;420(5):377-83.

29. McCormick D, Hall PA. The complexities of proliferating cell nuclear antigen. Histopathology. 1992;21(6):591-4.

30. Bravo R, Macdonald-Bravo H. Existence of two populations of cyclin/ proliferating cell nuclear antigen during the cell cycle: association with DNA replication sites. J Cell Biol. 1987;105(4):1549-54.

31. Myoung H, Kim MJ, Lee JH, Ok YJ, Paeng JY, Yun PY. Correlation of proliferative markers (Ki-67 and PCNA) with survival and lymph node metastasis in oral squamous cell carcinoma: a clinical and histopathological analysis of 113 patients. Int J Oral Maxillofac Surg. 2006;35(11):1005-10.

32. Watanabe $\mathrm{S}$, Watanabe R, Oton-Leite AF, Alencar Rde C, Oliveira JC, Leles $C R$, et al. Analysis of cell proliferation and pattern of invasion in oral squamous cell carcinoma. J Oral Sci. 2010;52(3):417-24.

33. Cortegoso AVB, Laureano NK, Silva ADD, Danilevicz CK, Magnusson AS, Visioli F, et al. Cell proliferation markers at the invasive tumor front of oral squamous cell carcinoma: comparative analysis in relation to clinicopathological parameters of patients. J Appl Oral Sci. 2017;25(3):318-23.

34. Störkel S, Reichert T, Reiffen KA, Wagner W. EGFR and PCNA experession in oral squamous cell carcinomas - a valuable tool in estimating the patient's prognosis. Eur J Cancer B Oral Oncol. 1993;29(4):273-7.

\section{Publisher's Note}

Springer Nature remains neutral with regard to jurisdictional claims in published maps and institutional affiliations.

\section{Ready to submit your research? Choose BMC and benefit from}

- fast, convenient online submission

- thorough peer review by experienced researchers in your field

- rapid publication on acceptance

- support for research data, including large and complex data types

- gold Open Access which fosters wider collaboration and increased citations

- maximum visibility for your research: over $100 \mathrm{M}$ website views per year

At BMC, research is always in progress.

Learn more biomedcentral.com/submissions 